MIRIAM RODRIGUEZ FERNANDES

\title{
A INFLUÊNCIA DA ANTIBIOTICOTERAPIA NA MICROBIOTA FECAL DE CRIANÇAS EM IDADE ESCOLAR
}

Dissertação apresentada ao Programa de Pós-graduação em Microbiologia do Instituto de Ciências Biomédicas da Universidade de São Paulo para obtenção do Título de Mestre em Ciências.

Área de Concentração: Microbiologia

Orientador: Prof. Dr. Mario Julio Avila-

Campos

Co-orientador: Profa. Dra. Viviane Nakano

Versão original

São Paulo

2015 


\section{RESUMO}

FERNANDES, M. R. A influência da antibioticoterapia na microbiota fecal de crianças em idade escolar. 2015. 111 f. Dissertação (Mestrado em Microbiologia) Instituto de Ciências Biomédicas, Universidade de São Paulo, 2015.

A microbiota intestinal é um ecossistema de alta complexidade e o conhecimento sobre suas interações com o hospedeiro ainda é bastante limitado. De todas as influências exógenas que possam alterar a microbiota intestinal, os agentes antimicrobianos são capazes de causar as mais rápidas e drásticas mudanças. $O$ impacto da exposição aos antimicrobianos na microbiota intestinal causa diminuição no número de determinados gêneros e espécies, dependendo do antimicrobiano utilizado, da dose e do tempo de exposição. A espécie Escherichia coli é a bactéria facultativa mais predominante na microbiota intestinal; quando são submetidas ao efeito dos antimicrobianos podem tornar-se resistentes, sendo consideradas reservatório de genes, capazes de adquirir e de transferir genes as outras bactérias da microbiota residente. Assim, o objetivo deste estudo foi analisar de forma comparativa alguns microrganismos que compõem a microbiota fecal de crianças com e sem antibioticoterapia em idade escolar; bem como avaliar a susceptibilidade aos antimicrobianos e os genes de resistência envolvidos. Foram coletadas amostras fecais não diarreicas de 30 crianças sem antibiótico (controle) e 31 de crianças com antibioticoterapia, com idade de 3 a 12 anos. $\mathrm{Na}$ análise quantitativa foi observada redução no número de cópias por g/fezes de: Bifidobacterium spp., Bacteroides fragilis, Clostridium perfringens, Escherichia coli, Methanobrevibacter smithii e do filo Firmicutes nas amostras das crianças que utilizaram antibióticos em relação ao grupo controle, exceto para Lactobacillus spp. e Parabacteroides distasonis que apresentaram uma quantificação maior no grupo antibiótico quando comparados com grupo controle. E. coli foi isolada em $26(86,7 \%)$ crianças controles e em $23(74,2 \%)$ crianças tratadas com antibióticos. As DEC identificadas no grupo controle foram: EAECa (50\%), EAECt (7,14\%), EPECa (21,4\%), ETEC-LT (14,3\%), STEC-stx1 $(7,14 \%)$ e STEC-stx2 (7,14\%); e no grupo tratado com antibióticos: EPECa $(66,6 \%)$ e EAECa $(33,3 \%)$. A resistência foi verificada para diversas drogas no grupo controle exceto para ciproflixacina, meropenem e tigeciclina; entretanto o grupo com antibioticoterapia apresentou elevada resistência para todas as drogas avaliadas, caracterizando os isolados desse estudo como MDR. Todos os isolados do grupo controle e antibióticos albergaram diversos genes de resistência, entretanto o gene blaKPC foi o único não detectado nos isolados do grupo controle. A análise da diversidade genética por AP-PCR mostrou boa discriminação entre os isolados e elevada diversidade genética. No grupo controle foram verificados 14 grupos genéticos com $85 \%$ de similaridade e no grupo com antibioticoterapia foram 24 agrupamentos com $86 \%$ de similaridade. Desta forma, nossos dados demonstram que a antibioticoteria causa alterações qualitativas e quantitativas na microbiota intestinal levando à diminuição da diversidade e a supressão de microrganismos; além disso, a elevada resistência as diversas classes de antimicrobianos das cepas de $E$. coli, bem como a presença de diversos genes de resistência ressalta a importância de cepas comensais serem MDR e albergarem esses genes.

Palavras chave: Microbiota intestinal. Crianças. Antimicrobianos. Escherichia coli. Escherichia coli diarreiogênica. Resistência bacteriana. PCR quantitativo. 


\begin{abstract}
FERNANDES, M. R. The influence of antibiotic therapy in fecal microbiota of schoolchildren. 2015. 111 p. Dissertação (Mestrado em Microbiologia) Instituto de Ciências Biomédicas, Universidade de São Paulo, 2015.

The intestinal microbiota is a complexity ecosystem and the understanding of this system and their interactions with the host is still limited. Of all the exogenous influences that may alter the intestinal microbiota, antimicrobial agents are able to cause the more rapid and dramatic changes. The impact of exposure to antimicrobial agents on intestinal microbiota causes a decrease in the number of certain genera and species, depending on the antimicrobial agent used, dose and duration of exposure. The species Escherichia. coli is facultative bacterium more predominant in intestinal microbiota, when it is subject to the effect of antimicrobial may become resistant, being considered reservoir of genes, capable of acquiring and transferring genes other bacteria of resident microbiota. Thus, the aim of this study was to analyze comparatively some microorganisms that composing the fecal microbiota of children with and without antibiotic therapy in school age; and evaluate the antimicrobial susceptibility and resistance genes involved. Stool samples (not diarrhea) were collected of 30 children without antibiotic (control) and 31 children with antibiotic therapy, aged 3 to 12 years. In quantitative analysis was observed decrease in the number of copies per g/feces: Bifidobacterium spp., Bacteroides fragilis, Clostridium perfringens, Escherichia coli, Methanobrevibacter smithii and the phylum Firmicutes in samples of children with antibiotic therapy in relation to control group, except Lactobacillus spp. and Parabacteroides distasonis that showed a higher quantification in the antibiotics group when compared with control group. E. coli was isolated in 26 $(86.7 \%)$ children controls and in $23(74.2 \%)$ children treated with antibiotics. DEC identified in control group were: aEAEC (50\%),tEAEC (7.14\%), aEPEC (21.4\%), ETECLT (14.3\%), STEC-stx1 (7.14\%) and STEC-stx2 (7.14\%); and in antibiotics group: aEPEC $(66.6 \%)$ and aEAEC (33.3\%). The resistance was verified for several drugs in the control group except for ciprofloxacin, meropenem and tigecycline; however the group with antibiotic therapy showed high resistance to all drugs evaluated, characterizing isolates of this study as MDR. All isolates from control group and antibiotics harbored several resistance genes, however bla KPC $_{\text {gene was the only one }}$ not detected in isolates from the control group. The analysis of genetic diversity by APPCR showed good discrimination between the isolates and high genetic diversity. In the control group were observed 14 clusters with $85 \%$ similarity and the antibiotics group were 24 clusters with $86 \%$ similarity. Thus, our data demonstrate that the antibiotic therapy cause qualitative or quantitative changes in intestinal microbiota leading to a decrease in the diversity and the elimination of microorganisms; in addition, the high resistance the various classes of antimicrobial of the strains of E. coli, as well as the presence of several genes of resistance highlights the importance of commensal strains are MDR and harboring these genes.
\end{abstract}

Keywords: Intestinal microbiota. Children. Antimicrobials. Escherichia coli. Diarrheogenic Escherichia coli. Bacterial resistance.Quantitative PCR. 


\section{INTRODUÇÃO}

A microbiota intestinal é um ecossistema de alta complexidade e o entendimento deste sistema e suas interações com o hospedeiro ainda é bastante limitado. Sabe-se que a microbiota tem importante papel na saúde, é constituída por diversos microrganismos que vivem simbioticamente no trato intestinal dos seres humanos e animais, e desepenha diferentes funções como: modulação imunológica, barreira protetora aos microrganismos patogênicos e contribuição nos processos metabólicos e nutricionais (BENGMARK, 1998; PENDERS, 2006).

Os microrganismos que compõem a microbiota intestinal humana são referidos coletivamente como microbiota indígena, residente ou autôctone, e vivem aderidos as mucosas do trato intestinal, sendo predominante as bactérias anaeróbias e os principais gêneros encontrados são: Bacteroides spp., Bifidobacterium spp., Eubacterium spp., Clostridium spp., Lactobacillus spp., Fusobacterium spp. e cocos gram positivos. Há também os microrganismos referidos como microbiota transitória ou exógena, no qual são bactérias provenientes do ambiente e não apresentam a capacidade ou não encontram condições apropriadas para se estabelecer, como no caso das Escherichia coli diarreiogênicas (DEC), que podem ser encontradas em pacientes assintomáticos (ALVAREZ et al., 2010; BARBOSA et al., 2010).

A microbiota fecal é o reflexo da composição da microbiota intestinal, pórem sabe-se que a microbiota fecal representa apenas os microrganimos do lúmen da região reto-sigmóide, diferindo da região íleo-cecal, das superfícies das mucosas das criptas e vilosidades, havendo assim diferença nas populações de microrganismos na região superior e inferior do intestino (HILL; DRASAR, 1975). O número de microrganismos encontrados no intestino adulto pode variar em até 800 espécies diferentes pertencentes a diversos gêneros, entretanto uma porção significativa não pode ser cultivada pelas técnicas existentes (HOLZAPFEL et al., 1998, SHEN et al., 2013). 


\subsection{Microbiota intestinal residente}

A colonização do trato intestinal é determinada por diversos fatores internos e externos do hospedeiro. Os fatores internos são: fisiologia e anatomia do trato intestinal, sais biliares, peristaltismo, $\mathrm{pH}$ e imunomodulação. Desta forma, a competição entre microrganismos por receptores de mucosa e as interações entre microrganismo-hospedeiro modulam sua composição, tornando a microbiota intestinal única para cada indivíduo (STEWART et al., 2005; TOIVANEN et al., 2001).

Estudos sugerem que a seleção inicial de bactérias no trato intestinal pode ser influenciada de forma genética (MENG et al., 2014). Há hipóteses de que os padrões dos sítios de adesão bacteriana sejam influenciados pela genética do indivíduo. Alguns estudos já demonstraram uma semelhança maior entre o padrão da microbiota de gêmeos idênticos em comparação a irmãos não gêmeos (STEWART et al., 2005; ZOETENDL et al., 2001).

Entre os fatores externos estão: composição da microbiota materna, tipo de parto, aleitamento, condições de higiene e uso de antimicrobianos. Em crianças nascidas de parto normal, a colonização da microbiota é iniciada por bactérias originadas do trato vaginal materno, já nas crianças nascidas de parto cesárea a colonização inicial é caracterizada pela presença de bactérias facultativas e esporuladas que podem ser adquiridas do ambiente hospitalar e dos profissionais de saúde. Poucas horas após o nascimento esses microrganismos podem ser detectados nas fezes do recém nascido (ALVAREZ et al., 2010; BACKHED, 2005; BEZIRTZOGLOU, 1997; FANARO et al., 2003).

Durante muitos anos, acreditou-se que o útero materno era um ambiente estéril e que a microbiota intestinal era estabelecida no momento do nascimento, sendo as primeiras bactérias a colonizarem 0 intestino as facultativas e anaeróbias estritas. Nos últimos anos, essa teoria está sendo questionada e observada de forma mais cautelosa através do "dogma do útero materno" que propõem que esse ambiente não é ausente de microrganismos (FUNKHOUSER; BORDENSTEIN, 2013; MOLES et al., 2013).

Alguns estudos mostraram a presença de algumas espécies como: Enterococcus faecium, Staphylococcus epidermidis, Propionibacterium acnes, Lactobacillus rhamnosus e Bifidobacterium spp., no sangue do cordão umbilical 
e anexos placentários (DiGIULIO et al., 2005; JIMENÉZ et al., 2005; SATOKARI et al., 2009). Foram observados também no mecônio, primeira evacuação do recém nascido, a presença de bactérias como Staphylococcus spp., Escherichia coli, Enterococcus spp. e Leuconostoc spp. sendo antes considerado estéril em uma gestação sem infecções (GONSALBES et al., 2013; JIMENÉZ et al., 2005; MOLES et al., 2013).

Funkhouser e Bordenstein, (2013) sugerem que as bactérias atravessam a placenta via corrente sanguínea após a translocação intestinal enquanto o epitélio intestinal previne a penetração de microrganismos; células dendríticas presentes no tecido linfóide associado ao intestino (Gut-associated lymphoid tissue - GALT) e Placas de Peyer, conseguem emitir seus prolongamentos através das células epiteliais, capturar e transportar as células bacterianas para os linfonodos, atingindo assim a corrente sanguínea. Entretanto essa teoria ainda é recente, e gera diversas dúvidas como as bactérias intestinais chegam a vida intrauterina.

Após o nascimento o intestino apresenta um potencial de óxido-redução positivo, sendo a colonização iniciada por bactérias aeróbias e facultativas, onde as espécies mais encontradas são: Staphylococcus spp., Enterococcus spp., Escherichia coli, Proteus mirabilis, Enterobacter cloacae e Serratia spp. Com o consumo de oxigênio, ocorre o predomínio de bactérias anaeróbias como: Bifidobacterium spp., Clostridium spp., Bacteroides spp., Eubacterium spp., Lactobacillus spp., Veillonella spp. e Fusobacterium spp. (BEZIRTZOGLOU, 1997; YON et al., 2015).

O leite materno materno contém nutrientes necessários ao desenvolvimento do recém nascido como: proteínas, cálcio, fosfato, oligossacarídeos e também fatores protetores como imunoglobulina $(\lg A)$, fator determinante na composição inicial da microbiota intestinal de lactentes (BEZIRTZOGLOU, 1997; CIVARDI et al., 2014; MONIRA et al., 2011).

Em crianças alimentadas com leite materno devido a presença de oligossacarídeos (conhecidos como fator "bifidogênico") a microbiota é predominada por Bifidobacterium spp., que produzem grandes quantidades de acetato e de lactato, limitando o crescimento de microrganismos como Escherichia coli e Clostridium perfringens (MONIRA et al., 2011; WOLOWCZUK et al., 2008). Observa-se também uma taxa mais elevada na 
colonização por Staphylococcus spp. em crianças alimentadas por leite materno devido o contato prolongado com a pele da mãe durante a amamentação, já a colonização por cocos anaeróbios dos gêneros Peptostreptococcus e Peptococcus ocorem geralmente após a introdução de alimentos sólidos (ARRIETA et al., 2014; BEZIRTZOGLOU, 1997).

Em recém nascidos alimentados com leite de fórmula observa-se maior predomínio de Bacteroides spp., Clostridium spp. e Enterococcus spp. em relação aos alimentados com leite materno (ADLERBERTH; WOLD, 2008). Cada vez mais os leites de fórmula vêem sendo modificados para se assemelharem ao leite materno, havendo adição de prebióticos. Observa-se a presença de Bifidobacterium spp. e Lactobacillus spp. nesta microbiota, entretanto esses lactentes são mais susceptíveis as infecções gastrointestinais, por não receber anticorpos protetores maternos e pela má higienização das mamadeiras (HASCOET et al., 2011; SAAVEDRA; DATTILO, 2012).

O grau de contaminação ambiental parece ser um outro fator diferencial no processo de colonização intestinal sendo descritas diferenças nítidas entre crianças nascidas em países desenvolvidos e subdesenvolvidos. Observa-se que crianças nascidas em países subdesenvolvidos são mais colonizadas por membros da família Enterobacteriaceae e Enterococcus spp. (ADLERBERTH; WOLD, 2008) provavelmente associados as condições socioeconômicas da população, além de fatores nutricionais e de higiene.

De todas as influências exógenas que possam alterar a microbiota intestinal, os agentes antimicrobianos são capazes de causar as mais rápidas e drásticas mudanças na microbiota residente. Por causa da perturbação que muitas drogas antibacterianas provocam no ecossistema intestinal, a resistência à colonização pode ser diminuída ou perdida. $O$ principal efeito observado inclui a supressão de bactérias anaeróbias, com exceção do Clostridium spp. que permanece em níveis detectáveis e a seleção de bactérias resistentes (Figura 1) (JERNBERG et al., 2010).

Estudos sobre os impactos da exposição aos antimicrobianos na microbiota intestinal relatam que existe diminuição, algumas vezes mais acentuadas, de determinados gêneros e espécies e que isso depende do antimicrobiano utilizado, da dose e do tempo de exposição (JERNBERG et al., 2010). Entre os microrganismos que mais sofrem esse tipo de alteração estão 
as enterobactérias, enterococos e bactérias anaeróbias (NORD; EDLUND, 1991; RAFIl et al., 2008).

Há relatos em que a $E$. coli pode ser substituída por Klebsiella spp. quando antibióticos são administrados (KLEESSEN et al., 2000; NICOLI, 1995; NICOLI; VIEIRA, 2004). Mais recentemente, o surgimento da diarreia associada ao uso de antibióticos e a colite causada pelo Clostridium difficile, aumentou a consciência geral de que era possível a doença surgir devido às alterações ocorridas na microbiota residente. A influência do uso de antimicrobiano na microbiota intestinal é transitória, mas pode persistir por algum período após o término do uso (RILEY, 2010).

Figura 1 - Representação do impacto da administração de antibióticos na comunidade bacteriana.

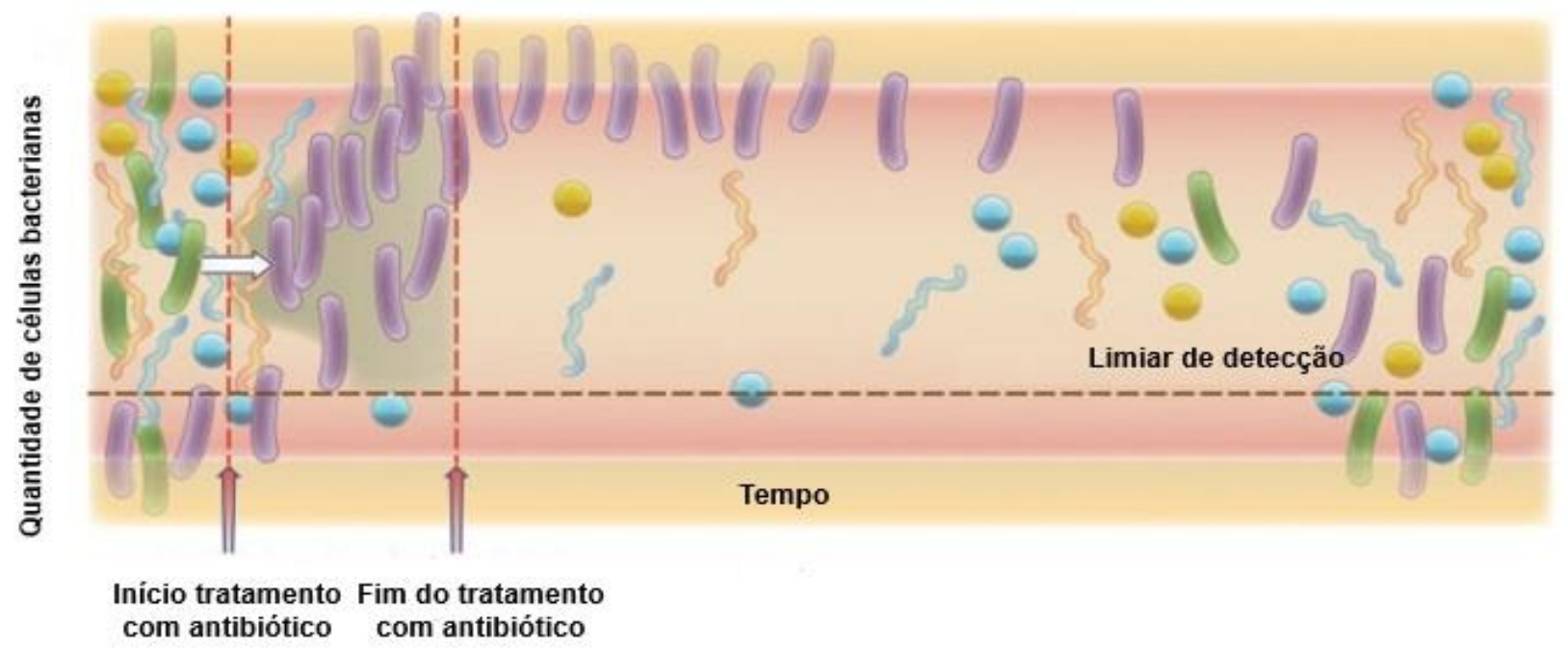

Fonte adaptado de Jernberg et al., (2010).

Outros fatores que influenciam a composição da microbiota podem ser: diarreias, enterocolites, doença inflamatória, diabetes e a prematuridade do parto. Sabe-se que crianças prematuras tem retardo no processo de colonização da microbiota intestinal, associado aos fatores externos (uso de antimicrobianos) e internos (imaturidade celular) (BUFFIE; PAMER, 2013; PENDERS, 2006). 
A microbiota intestinal tem efeito estimulante no desenvolvimento do sistema imunológico; está envolvida em aspectos de resistência nos estágios iniciais das infecções por patógenos. No trato intestinal existe um estado constante de modulação, pois ao mesmo tempo que o sistema imunológico está pronto para agir contra bactérias patogênicas ele é capaz de manter-se tolerante em relação a microbiota (WINKLER et al., 2007).

Além da ativação imunológica a microbiota desempenha papeis importantes na resistência à colonização de bactérias patogênicas, devido a produção de substâncias antagonistas, competição por nutrientes e por sítios de adesão (TANNOCK,2001; WINKLER et al., 2007).

A função da microbiota intestinal também pode estar relacionada com a nutrição e metabolismo do hospedeiro, evidenciada, por exemplo, por interferir no $\mathrm{pH}$ do intestino e na motilidade intestinal, favorecendo absorção de íons e água, e na produção de vitamina K (LIN et al., 2005). A microbiota também é responsável pela fermentação de uma série de substratos como os carboidratos não digeríveis da dieta, que chegam ao lúmen intestinal e são transformados em ácidos graxos de cadeia curta (Short-chain fatty acids SCFAs) por bactérias sacarolíticas (MAGALHAES et al., 2007).

Apesar de todos esses benefícios, a microbiota intestinal pode estar envolvida em processos patológicos como: alergias, obesidade, câncer de cólon e doença inflamatória intestinal, provavelmente devido a alteração desta população (ARRIETA et al., 2014; BERVOETS et al., 2013; COX; BLASSER, 2013; KOVATCHEVA-DATCHARY, 2009).

No primeiro ano de vida de uma criança, a microbiota ainda é considerada instável. Entretanto, vários fatores (alimentação, hábitos de higiene, utilização de antimicrobianos e o próprio sistema imunológico) atuam em conjunto modulando o processo de instalação da microbiota intestinal, de forma que um pode influenciar ou alterar o efeito do outro. Sabe-se que a microbiota intestinal torna-se estável a partir dos 2 anos de idade, após esse período a microbiota assemelha-se a dos adultos (PALMER et al, 2007).

Dentre os diversos microrganismos que compõem a microbiota intestinal os filos Bacteroidetes e Firmicutes correspondem a mais de $90 \%$ do total de bactérias (SHEN et al., 2013). Alguns gêneros encontrados também merecem destaque como: Bifidobacterium spp. conhecidos pelos seus efeitos benéficos 
para saúde humana, sendo denominadas bactérias probióticas, assim como Lactobacillus spp., ambos encontrados na microbiota de crianças amamentadas por leite materno e de fórmula (MONIRA et al., 2011; RUSSEL et al., 2011).

Outros microrganismos de importância na microbiota intestinal são aqueles pertencentes aos gêneros Bacteroides/Parabacteroides sendo as espécies mais encontradas: $B$. vulgatus, $P$. distasonis, $B$. fragilis, $B$. ovatus, $P$. merdae e $B$. thetaiotaomicron. São considerados patógenos oportunistas, particularmente a espécie $B$. fragilis, por apresentar uma variedade de fatores de virulência e principalmente pela sua resistência aos diversos antimicrobianos (WEXLER, 2007).

As espécies do gênero Clostridium são pertencentes à microbiota residente do intestino de humanos e animais. Em crianças, espécies pertencentes ao Cluster I e ao Cluster XI são as mais predominantemente encontradas, das quais se destacam: $C$. perfringens e $C$. difficile, por estarem envolvidos em diversas infecções como: enterites e gangrena gasosas; e colite pseudomembranosa associada à antibioticoterapia (ADLERBERTH; WOLD, 2009; COLLINS et al., 1994;).

Bactérias metanogênicas do domínio Archaea, são anaeróbias estritas e fazem parte da microbiota residente do intestino humano, sendo Methanobrevibacter smithii a espécie mais encontrada. A colonização intestinal com metanogênicas é iniciada nas primeiras semanas após o nascimento. Seu número varia de $10^{10}$ microrganismos por grama de peso seco, sendo que um terço da população carrega $10^{8}-10^{10}$ microrganismos por gramas de fezes. As Archaea possuem uma variedade de características estruturais e metabólicas únicas que não são encontradas em Bacteria, incluindo a falta de sítios alvos para os antibióticos comuns (DERMOUMI; ANSORG, 2001; DRIDI et al., 2011).

Escherichia coli constitui um grupo heterogêneo de bactérias tipicamente não patogênicas que fazem parte da microbiota intestinal. Após o processo de colonização estes microrganismos convivem com seu hospedeiro na maioria das vezes pelo resto da vida, sendo a principal bactéria facultativa presente no intestino (KAPER et al., 2004). Entretanto quando o hospedeiro encontra-se imunodeprimido ou quando as barreiras gastrointestinais são violadas, até 
mesmo cepas de E. coli não patogênicas podem causar infecção (NATARO; KAPER, 1998).

Existem diferenças na distribuição das bactérias em cada compartimento intestinal como: no lúmen intestinal, na camada de muco que recobre o epitélio intestinal e outras aderidas aos enterócitos. Há poucos estudos avaliando a composição da microbiota da mucosa intestinal devido a dificuldade de se obter espécimes que representariam a composição desse sítio, e a escassez de estudos longitudinais para melhor compreensão desse sistema (ADLERBERTH; WOLD, 2008).

\subsection{Escherichia coli}

O gênero Escherichia pertence à família Enterobacteriaceae, são caracterizadas por serem gram negativas, bacilos não formadores de esporos, facultativas, oxidase negativa, imóveis ou móveis por flagelos peritríquios (KAPER et al., 2004; WEINTRAUB, 2007). Há seis espécies descritas de Escherichia: E. coli, E. blattae, E. fergussonii, E. vulneris, E. albetii, E. hermannii, sendo a E. coli a espécie mais comumente estudada (HUYS et al., 2003).

Foi identificada pela primeira vez em 1885 pelo pediatra alemão Theodor Escherich e desde então verifica-se que pode ser encontrada em diferentes ecossistemas. É a principal bactéria facultativa presente na microbiota intestinal de animais e humanos, por ser um microrganismo bem diversificado em seus aspectos fisiológicos, ecológicos e patogênicos (HUYS et al., 2003; TORRES et al., 2010).

Costumam ser classificadas em vários patotipos e sorotipos, identificadas por antissoros específicos preparados contra antígenos: $O$ (somáticos), $\mathrm{K}$ (capsular) e H (flagelar). A combinação entre eles possibilita a discriminação de E. coli em mais de 50.000 sorotipos, contudo poucos são considerados patogênicos (KAPER et al., 2004; NATARO; KAPER, 1998;).

Nas primeiras horas de vida da criança, E. coli pode ser encontrada colonizando o hospedeiro; entretanto algumas cepas no processo de adaptação do ecossistema intestinal, adquiriram fatores de virulência, que 
proporcionaram algumas combinações genéticas bem sucedidas, conferindo a capacidade de causar doenças. A maioria das E. coli não são patogênicas, porém algumas estão envolvidas em processos infecciosos como: diarreias, infecções do trato urinário, septicemias, meningites. Podendo então ser classificadas como: comensais, patogênicas intestinais ( $E$. coli diarreiogênica $D E C)$ e patogênicas extra intestinais ( $E$. coli extra intestinal - ExPEC) (CROXEN; FINLAY, 2010) (Figura 2).

Figura 2 - Sítios de colonização de E. coli patogênica.

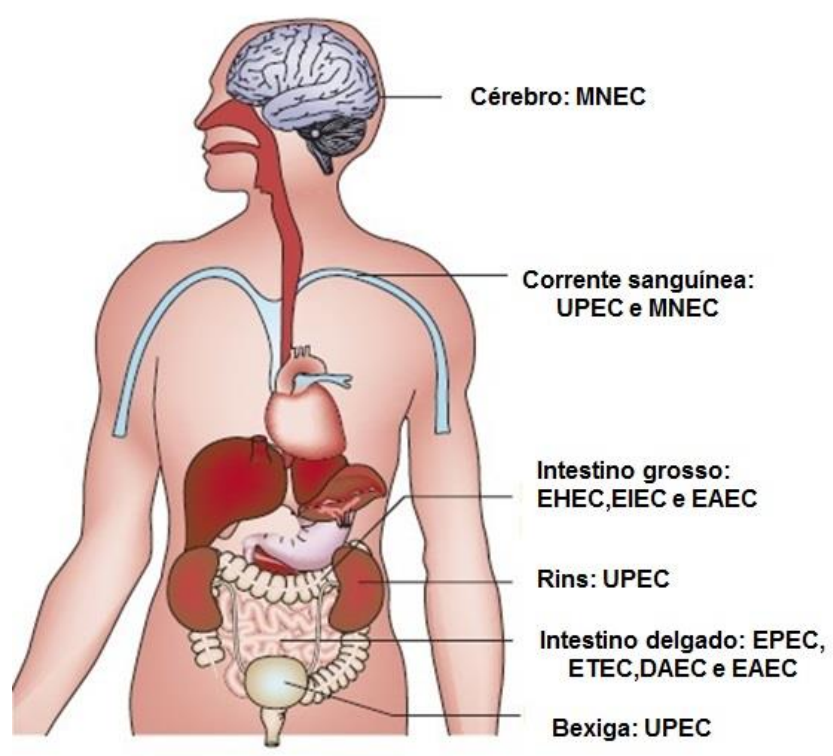

Fonte: adaptado de Croxen e Finlay, 2010.

As EXPEC estão associadas as diversas infecções como: do trato urinário sendo chamadas de UPEC (E. coli uropatogênica), sepses (associadas as infecções urinárias) e as meningites (MNEC - E. coli causadora de meningite neonatal) (CROXEN; FINLAY, 2010).

As infecções urinárias são muito frequentes na comunidade e em ambientes hospitalares, sendo que $70-90 \%$ são ocasionadas por UPEC. Essas bactérias agem como patógenos oportunistas causando diversas manifestações clínicas como: bacteriuria, cistite e pielonefrite e podem estar presentes em 20\% dos indivíduos saudáveis (BRUMBAUGH; MOBLEY, 2012; JOHNSON et al., 2005). As MNEC apresentam uma alta taxa de morbidade e 
mortalidade em neonatos; enquanto que $10 \%$ dos casos ocorre em crianças entre 1 e 3 meses de idade (BONACORSI; BINGEN, 2005).

\subsubsection{Escherichia coli diarreiogênicas (DEC)}

A diarreia infecciosa é um grande problema de saúde pública mundial, sendo responsável por milhares de mortes todos os anos em crianças menores de 5 anos de idade, principalmente em países em desenvolvimento. Dentre os principais agentes estão: E. coli diarreiogênicas, Shigella spp., Salmonella spp. Yersinia enterocolitica e Campylobacter jejuni (NAVENEETHAN; GIANNELA, 2008).

A identificação DEC não pode ser baseada apenas em critérios de cultivo e testes bioquímicos, uma vez que são indistinguíveis de $E$. coli comensal. Além disso a sorotipagem nem sempre está correlacionada com a patogenicidade, sendo a melhor a forma de identificação através de testes de adesão em células eucarióticas e a análise molecular de seus fatores de virulência (BUERIS et al., 2007).

As amostras de DEC são divididas em seis patotipos, de acordo com seus fatores de virulência e pelos mecanismos que ocasionam a doença intestinal sendo: $E$. coli enteropatogênica (EPEC), E. coli enterotoxigênica (ETEC), E. coli enteroinvasora (EIEC), E. coli produtora de toxina Shiga (STEC), E. coli enteroagregativa (EAEC), E. coli que adere difusamente as células epiteliais (DAEC). Sabe-se que alguns desses patotipos incluem algumas variações, como no caso das $E$. coli enterohemorrágica (EHEC) que são uma subcategoria de STEC e as EAEC e EPEC que foram subdivididas em típicas e atípicas (CROXEN; FINLAY; 2010; KAPER et al., 2004). Os diferentes patotipos de DEC causam sintomas intestinais muito particulares e são intimamente relacionados com suas estratégias de virulência (Figura 3). 
Figura 3 - Representação dos seis patotipos de E. coli diarreiogênicas.
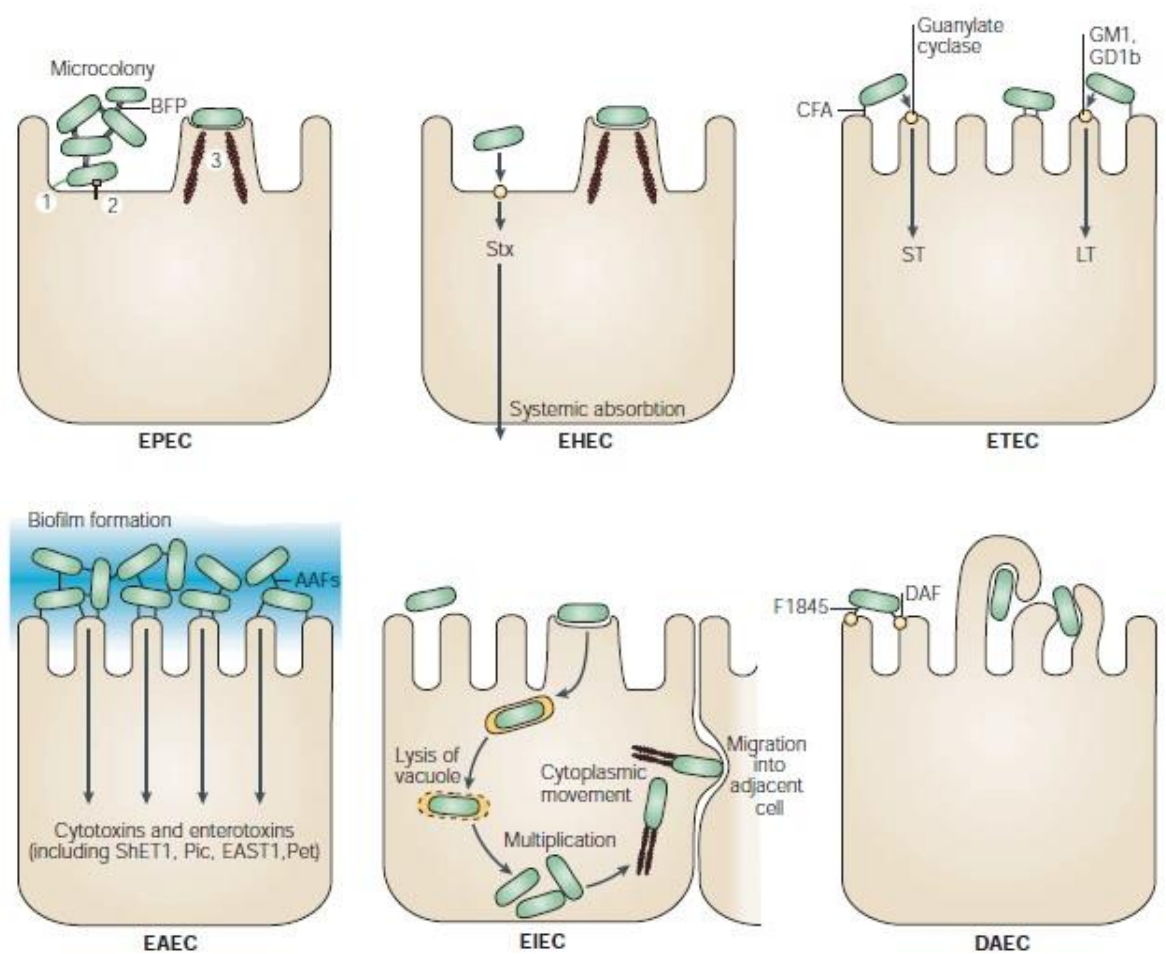

1: adesão inicial; 2:proteínas de translocação (sistema de secreção tipo III); 3: formação do pedestal.

Fonte: Kaper et al., (2004).

Recentemente dois outros patotipos surgiram: E. coli aderente e invasora (AIEC) associada a doença de Crohn e E. coli enteroagregativa produtora de toxina de Shiga (STEAEC), que foi responsável pelo surto ocorrido na Alemanha em 2011 que se espalhou por diversos países da Europa, além da América do Norte tendo um grande impacto sobre o comércio internacional de alimentos (CLEMENTS et al., 2012).

As E. coli enteropatogênicas (EPEC) são uma das causas mais comuns de diarreias em crianças de até um ano de idade nos países em desenvolvimento. Uma de suas principais características na patogênese é a formação de uma lesão histopatológica no epitélio intestinal denominada lesão A/E (attaching and effacing), que resulta da adesão íntima da bactéria ao enterócito e promove a desestruturação das microviolosidades do epitélio, levando à polimerização da actina e o rearranjo das proteínas do citoesqueleto, resultando na formação de estruturas semelhantes a um pedestal na membrana apical do enterócito sobre a qual a bactéria permanece aderida (NATARO; KAPER, 1998; NUNES et al., 2012; VIDAL et al., 2007). 
Atualmente as EPEC são divididas em duas subcategorias: EPEC típica (EPECt) e EPEC atípica (EPECa), sendo que ambas possuem o gene eae ( $E$. coli attaching and effacing), porém apenas as EPECt produzem um pilus tipo IV conhecido como BFP (Bundle forming pilus) expresso por genes plasmidiais de alto peso molecular conhecido como EAF (EPEC adherence factor) (VIDAL et al., 2007). A BFP é importante por promover a ligação inicial à célula hospedeira e a interação entre as bactérias, levando a formação de microcolônias aderidas. Nas EPECa como o BFP não é expresso, não há formação de agregados nas lesões $\mathrm{A} / \mathrm{E}$, mostrando agrupamentos mais frouxos das células bacterianas, ocasionando o padrão de adesão localizada like (LAL) (ARENAS-HERNÁNDEZ, 2012; GOMES et al., KAPER et al., 2004).

As $E$. coli enterotoxigênicas (ETEC) são caracterizadas pela produção de uma ou ambas enterotoxinas denominadas termolábil (LT) e termoestável (ST). No hospedeiro colonizam e aderem superficialmente aos enterócitos, e pela ação das toxinas causam diarreia aquosa por interferirem em mecanismos regulatórios da guanilase e adenilase ciclase, resultando em desequilibro hídrico e salino; acometendo crianças e adultos (FLECKENSTEIN et al, 2010; ISERI et al., 2011; KAPER et al., 2004).

O mecanismo de patogenicidade das E. coli enteroagregativas (EAEC) consiste na colonização bacteriana formando um padrão de adesão agregativo com aumento na produção de muco, causando diarreia aguda e persistente. Este fenótipo possui fímbrias de aderência agregativa do tipo I-IV (AAFI-IV), os genes responsáveis pela expressão dessas fímbrias estão presentes no plasmídeo pAA (plasmídeo de adesão agregativa) (KAPER et al., 2004; MORIN et al., 2013; NATARO, 1998; WEINTRAUB, 2007). De modo semelhante como ocorreu com as EPEC, Sarantuya et al., (2004) propuseram a classificação de EAEC nos grupos típicas e atípicas. A classificação baseiase na presença ou não do gene aggR (activator aggregative adherence regulator), que codifica uma proteína reguladora dos genes fimbriais de EAEC e que está localizada em plasmídeo.

$O$ patotipo de E. coli enteroinvasiva (EIEC) é geneticamente relacionado à Shigella spp., que invadem a mucosa intestinal e causam diarreia aquosa e colite inflamatória (NATARO; KAPER, 1998; SETHABUTR et al., 1993). Já as E. coli produtoras de Toxina Shiga (STEC) produzem citotoxinas semelhantes 
a "Toxina de Shiga" (stx1 e stx2) que ocasionam lesões celulares por afetarem a síntese proteica. Dentro desse patotipo existe uma subcategoria denominada E. coli enterohemorrágica (EHEC), que além da produção de citotoxinas, apresentam a capacidade de ocasionar a lesão $A / E$, sendo responsáveis por severos quadros de diarreia hemorrágica e síndrome hemolítica urêmica (SHU) (BERGAN et al., 2012; BERTIN et al., 2001).

O patotipo DAEC apresenta um padrão de aderência difusa em ensaio de adesão em células epiteliais. Ainda existem diversas controversias sobre 0 papel da DAEC em diarreias, uma vez que alguns estudos relatam que esse patotipo pode ser encontrado de forma semelhante em crianças com e sem diarreia. No Brasil, estudos em crianças com diarreia, a presença de DAEC foi associada em menores de 2 anos de idade (SCALETSKY et al., 2002), entretanto Lozer et al., (2013) reportou a correlação deste patotipo em crianças menores de 2 anos até 10 anos com casos de diarreia, bem como nas crianças sem diarreia.

\subsection{Antimicrobianos}

A descoberta dos antimicrobianos revolucionou a medicina, salvando inúmeras pessoas e têm sido prescritos para o tratamento de diversas infecções (DAVIES; DAVIES, 2010). Nos últimos anos, são produzidas toneladas de antimicrobianos para diversas finalidades, desde tratamento terapêutico e/ou profilático na medicina humana e animal, bem como para agropecuária. Entretanto, devido às más condutas como: o uso indiscriminado e o descarte indevido surgiram diversos ecossistemas com bactérias resistentes (DAVIES; DAVIES, 2010; ROCHA et al., 2011).

Os antimicrobianos são substâncias naturais (antibióticos) ou sintéticas (quimioterápicos) que agem sobre os microrganismos inibindo seu crescimento ou causando a sua destruição (SÁEZ-LLORENS, 2000). Podem ser classificados como: bactericidas (associado à morte bacteriana) ou bacteriostáticos (inibe o metabolismo bacteriano).

\subsubsection{Mecanismos de ação}

Os antimicrobianos possuem diversos mecanismos de ação, agindo em diferentes sítios alvos como: 
a) inibição da síntese da parede celular,

b) inibição da síntese de proteínas,

c) inibição da síntese de ácido fólico,

d) alteração na síntese de ácidos nucleicos e

e) alteração da permeabilidade da membrana celular (Figura 4) (ANVISA, 2007).

Os $\beta$-lactâmicos, glicopeptídeos, fosfomicina, bacitracina e cicloserina atuam na síntese da parede celular inibindo as ligações cruzadas da cadeia de peptideoglicano (transpeptidases - PBP: protein binding penicillin) causando a lise bacteriana. $O$ grupo dos $\beta$-lactâmicos incluem as: penicilinas, cefalosporinas, monobactâmicos, carbapênemicos, cefamicinas; e o grupo dos glicopeptídeos é composto por: vancomicina e a teicoplamina (CETINKAYA et al., 2000; LIVERMORE, 1995; POETA, 2006).

Os ribossomos bacterianos são estruturalmente diferentes dos eucariotos. As bactérias apresentam duas subunidades $30 \mathrm{~S}$ e $50 \mathrm{~S}$, enquanto que os eucariotos constituem as subunidades $40 \mathrm{~S}$ e $60 \mathrm{~S}$. Os antimicrobianos que atuam na síntese proteica ligam-se as subunidades ribossomais, interferindo com os estágios da síntese proteica (iniciação, elongação, translocação e terminação). As tetraciclinas, glicilciclinas, nitrofurano e os aminoglicosídeos ligam-se as subunidades 30S; cloranfenicol, macrolídeos, lincosamidas, oxazolidinonas atuam nas subunidades 50S (SEFTON, 2002; WALSH, 2003). 
Figura 4 - Mecanismos de ação dos antimicrobianos.

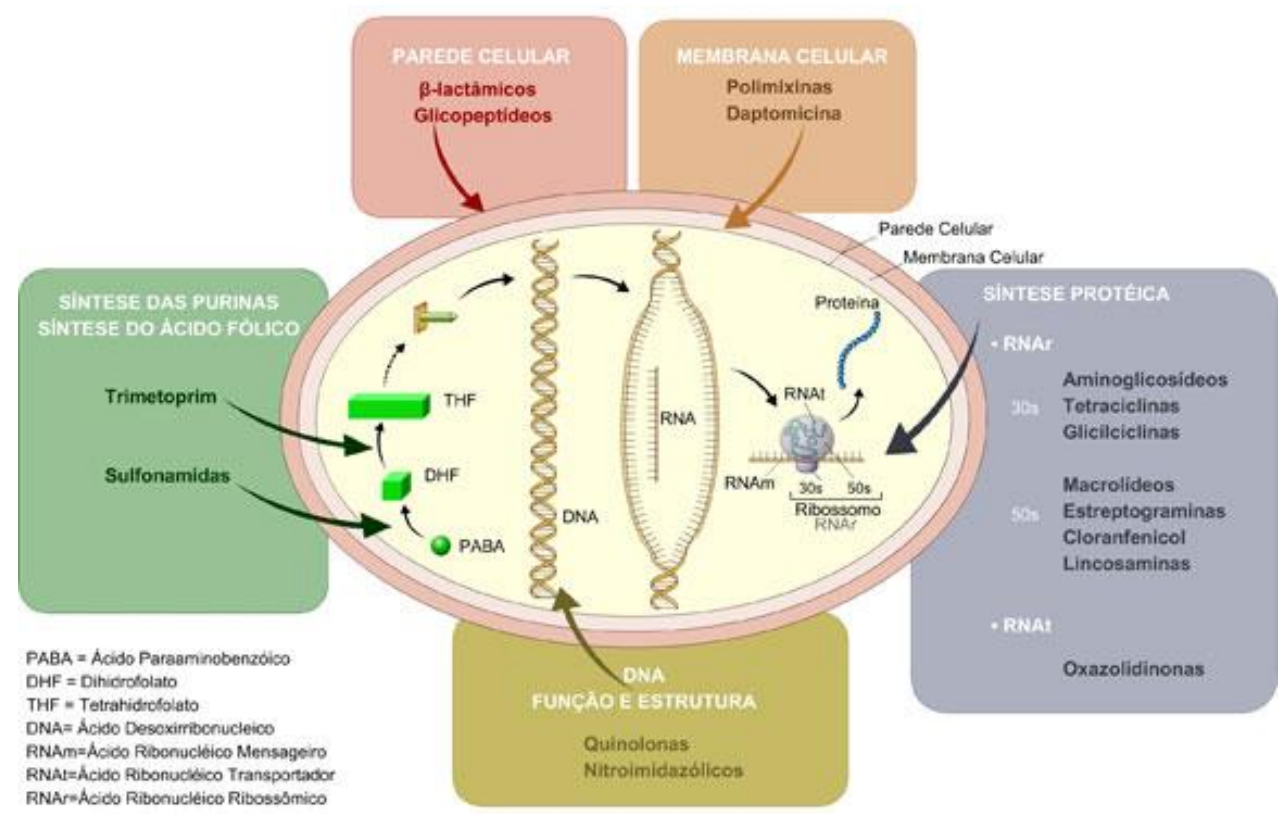

Fonte: ANVISA, 2007.

O ácido fólico desempenha um papel essencial em etapas da síntese das purinas e pirimidinas. As bactérias necessitam de ácido fólico mas não apresentam um sistema de obtenção deste ácido, sendo necessário sintetizar. As sulfonamidas e trimetoprim possuem suas estruturas moleculares semelhante ao substrato de duas enzimas: PABA (ácido paraminobenzóico) e DHF (ácido didrofólico), que produzem a forma ativa do ácido fólico THF (ácido tetrahidrofólico). A utilização combinada de sulfametoxazol e trimetoprima causam um duplo bloqueio no metabolismo do ácido fólico (HUOVINEN, 2001; SÁENZ, 2004).

Os antimicrobianos que interferem na síntese dos ácidos nucléicos são: a) quinolonas e nitroimidazol - atuando sobre DNA-girase (topoisomerases); b) rifamicinas - ligam-se à RNA polimerase DNA dependente, impedindo a síntese de RNAm (ALDRED at al., 2015; SEFTON, 2002; WALSH, 2003).

As polimixinas e lipopeptídeos ligam-se as membranas de bactérias gram negativas, desorganizando a estrutura, causando a alteração da permeabilidade e saída de constituintes intracelulares através da membrana (SEFTON, 2002). 
O uso descontrolado e a prescrição indiscriminada dos antimicrobianos contribuíram com disseminação da resistência bacteriana em microrganismos nosocomiais e comunitários. Entretanto, a descoberta e introdução de novos antimicrobianos diminuíram drasticamente nos últimos anos, e apesar da conscientização dos profissionais da saúde e da população, o uso indiscriminado ainda persiste (BASSETI et al., 2013; IDSA, 2011; SPELLBERG et al., 2008).

\subsubsection{Mecanismos de Resistência}

A resistência bacteriana pode ser definida como o conjunto de mecanismos as adaptações contra os efeitos nocivos ou letais aos quais as bactérias são expostas (LIVERMORE, 1995). Atualmente, a disseminação da resistência aos antimicrobianos estende-se além da clínica e é considerada um problema mundial de saúde pública, que varia dependendo da localidade e do país (WRIGHT, 2014).

Desde a introdução dos primeiros antimicrobianos, as bactérias desenvolveram vários mecanismos de resistência. Essa resistência pode ser intrínseca ou adquirida (GUARDABASSI, 2006). A resistência intrínseca é natural e evolutivamente conservada nos microrganismos; entretanto a resistência adquirida é resultado de mutações e transferência horizontal de genes (VAN HOEK et al., 2011).

A disseminação de bactérias resistentes é resultado da combinação de múltiplos fatores tais como: mutações nos genes de resistência que aumentam seu espectro de atividade, troca de informações genéticas nas quais genes de resistência são transferidos para novos microrganismos, pressão seletiva exercida pelas condições do meio as quais favorecem a proliferação de clones com resistência aos diversos antimicrobianos (ALANIS, 2005; BUSH et al., 1995).

Elementos genéticos podem conter vários genes de resistência de diferentes classes de antibióticos, conferindo as bactérias um fenótipo de multirresistência (MDR). A localização dos genes de resistência nestes elementos genéticos móveis (plasmídeos, transposons e integrons) torna possível a transferência da resistência entre as bactérias (SÁENZ, 2004).

Existem algumas definições para a resistência às múltiplas drogas como: MDR (Multidrug resistant), XDR (Extensively drug-resistant) e PDR (Pandrug 
resistant). As bactérias MDR se caracterizam por apresentarem resistência a três ou mais classes diferentes de antimicrobianos. As bactérias classificadas como XDR são definidas como resistentes a várias classes de antimicrobianos, sendo essa nomenclatura bastante utilizada para isolados de Mycobacterium tuberculosis resistentes aos agentes de primeira escolha. E PDR são considerados os isolados resistentes a todas as classes de antimicrobianos (MAGIORAKOS et al., 2011).

Os principais mecanismos de resistência podem ser observados na Figura 5 e são descritos como:

a) alteração da permeabilidade da membrana,

b) modificação ou proteção do sítio alvo,

c) modificação ou inibição enzimática e

d) bombas de efluxo.

Figura 5 - Mecanismos de ação e resistência aos antimicrobianos.

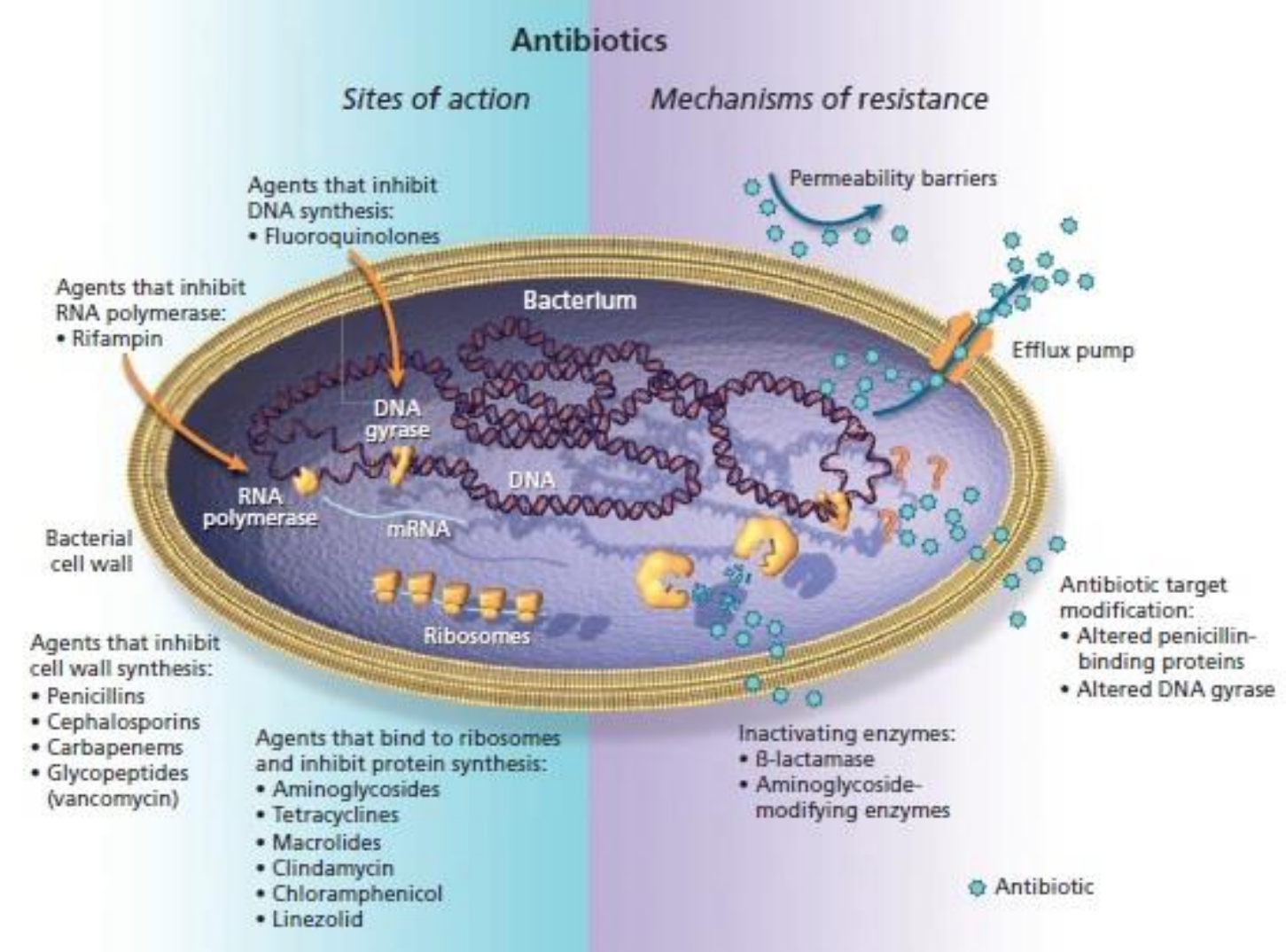

Fonte: Mulvey et al., 2009. 
Bactérias gram negativas são menos permeáveis a muitas drogas, devido a sua membrana externa. Antimicrobianos hidrofílicos atravessam a membrana externa por difusão através de porinas ancoradas na membrana. A alteração da permeabilidade da membrana, ocorre por perda ou alteração dos canais de porinas; este mecanismo resulta normalmente em mutações espontâneas exercida pela pressão seletiva dos antimicrobianos (BLAIR et al., 2014; SEFTON, 2002).

A modificação ou proteção do sítio alvo pode ser devido a dois processos: mutação do sítio onde o antimicrobiano se liga, provocando diminuição na afinidade e a produção de uma proteína que se liga ao local específico onde a droga atuaria (BLAIR et al., 2014).

Algumas bactérias produzem enzimas que podem modificar e inativar os antimicrobianos impedindo sua atividade. As enzimas mais conhecidas são as $\beta$-lactamases que catalisam a hidrólise do anel $\beta$-lactâmico, inativando 0 antimicrobiano impedindo sua ação contra as proteínas responsáveis pela síntese da parede celular (BUSH; JACOBY, 2010).

As $\beta$-lactamases de espectro estendido (ESBL) são capazes de hidrolisar cefalosporinas de terceira e quarta geração e o aztreonam, sendo inativadas por inibidores específicos como: clavulanato, sulbactam e tazobactam. Essas enzimas foram derivadas de mutações nos genes blaTEM $\mathrm{e}$ blasHV que resultaram da substituição de aminoácidos, alterando o substrato específico delas (BUSH; JACOBY, 2010; SILVA; LINCOPAN, 2012).

Outro mecanismo enzimático de resistência são as acetiltranferases, enzimas envolvidas com a resistência ao cloranfenicol (codificadas pelos genes cat) que acetilam a molécula de antibiótico impedindo a ligação com os ribossomos bacterianos (SÁENZ, 2004). Em aminoglicosídeos, a resistência pode ser através de absorção reduzida da droga ou modificação enzimática por acetilação (AAC), adenilação (ANT) ou fosforilação (APH) (FOUHY et al., 2014).

As bombas de efluxo são mecanismo de expulsão de substâncias nocivas aos microrganismos, incluindo os antimicrobianos. Esses sistemas normalmente não são substrato dependentes e estão relacionados com a multirresistência. A resistência relacionada com o sistema de efluxo é codificada por genes e proteínas presentes em plasmídeos ou no 
cromossomo, e são frequentemente associados com mecanismo de resistência intrínseco, permitindo a sobrevivência da bactéria a ambientes hostis (PIDDOCK, 2006a; WEBBER; PIDDOCK, 2003).

Os sistemas de efluxo bacteriano são classificados em famílias de proteínas transportadoras com base na homologia de sequências de aminoácidos, sendo dividida em cinco famílias: ATP- binding cassette (ABC), Major Facilator Superfamily (MFS), Resistence Nodulation Cell Division (RND), Small Multidrug Resistence (SMR) e Multidrug and Toxic Extrusion (MATE). Esses sistemas utilizam à força próton motiva como fonte de energia, exceto a família $A B C$ que utiliza a hidrólise do ATP para exportar os substratos (MOREIRA et al, 2004; WEBBER; PIDDOCK, 2003).

As bactérias gram negativas apresentam um arsenal de mecanismos de resistência aos antimicrobianos comumente utilizados na prática médica e vem tornando-se um obstáculo na conduta terapêutica contra infecções em pacientes hospitalizados. Em E. coli existe uma variedade de mecanismos de resistência descritos, sendo que são utilizados antimicrobianos de várias classes para diversas infecções. Dentre os principais mecanismos descritos para E. coli pode-se observar: produção de $\beta$-lactamases, metilação do RNA ribossomal, bombas de efluxo, modificação enzimática do antimicrobiano e mutações das DNA girases (BLAIR et al., 2014).

\subsection{Resistência aos antimicrobianos em Escherichia coli}

Dentre os membros da família Enterobacteriaceae, a espécie $E$. coli tem sido prevalente em infecções nosocomiais ao redor do mundo. Sua resistência é verificada e sabe-se que bactérias comensais são reservatórios de diversos genes de resistência (SEPP et al., 2009).

A resistência aos $\beta$-lactâmicos em $E$. coli é mediada principalmente por enzimas $\beta$-lactamases e uma grande variedade delas foram descritas e caracterizadas (DOMINGUEZ et al., 2002; LIVERMORE, 1995). As $\beta$ lactamases AmpC ( $\beta$-lactamase de classe $C$ ) podem ser codificadas por cromossomos ou plasmídeos, são capazes de conferir resistência para a maioria das penicilinas e para as cefalosporinas de terceira geração (JACOBY, 2009). No Brasil, a presença de AmpC plasmidial, tem sido reportada e em 
isolados de E. coli, o gene blacmy-2 foi correlacionado (PAVEZ et al., 2008; PEIRANO et al., 2006).

Desde as primeiras detecções das ESBL, estas enzimas têm mostrado grande capacidade de disseminação tanto em ambientes hospitalares quanto na comunidade, além de ser considerado um dos principais mecanismos de resistência em E. coli (BUSH; FISHER, 2011).

Em E. coli $90 \%$ da resistência associada a ampicilina está relacionada a produção de TEM-1 (Temoniera). Atualmente as enzimas CTX-M (Cefotaximases) têm sido as mais detectadas e no Brasil as mais prevalentes são: CTX-M-2, CTX-M- 8 e CTX-M-9 (QUEIROZ et al., 2012; SILVA; LINCOPAN, 2012). Cepas de E. coli produtora da enzima CTX-M-15, vêm emergindo desde 2003, como um importante patógeno da comunidade e em infecções adquiridas em hospital no mundo todo (PEIRANO; PITOUT, 2010).

Mundialmente as principais ESBL associadas com resistência $E$. coli são as TEM, CTX-M, SHV (Sulphydryl variable) e OXA (Oxacilinases) (SILVA; LINCOPAN, 2012). Infelizmente no Brasil, não existem programas de vigilância de abrangência nacional referentes à resistência bacteriana e a seus mecanismos, tornando-se difícil estimar a prevalência de cepas produtoras de ESBL.

O desenvolvimento da resistência aos carbapenêmicos em E. coli merece atenção, por ser muitas vezes a última terapia eficaz disponível para o tratamento de infecções graves. Entre as carbapenemases distribuídas mundialmente em E. coli estão: NDM (New Dehli metalo- $\beta$-lactamase) e OXA48 (PEIRANO et al., 2014).

Klebsiela pneumoniae produtora de carbapenemase (KPC) foi primeiramente identificada em $K$. pneumoniae, sendo rapidamente disseminada e o gene blaKPC é encontrado em outros gêneros da família Enterobacteriaeceae, inclusive em E. coli (PEIRANO; PITOUT, 2010). Existe grande preocupação com a aquisição do gene blakpc por E. coli, por ela pertencer a microbiota residente e servir como veículo de propagação em ambientes comunitários e hospitalares. Os dados epidemiológicos para E. coli produtora de blaKPC ainda permanecem relativamente escassos (OHARA et al., 2014). 
Um grande problema para terapêutica humana e animal é a resistência a classe das quinolonas. O principal mecanismo de resistência em quinolonas de E. coli inclui alterações do alvo molecular de ação associadas as mutações dos genes gyrA e parC (DOMINGUEZ et al., 2002; WIEDEMANN; HEISING, 1994;).

No Brasil a resistência para quinolonas associada a plasmídeos, tem aumentado nos isolados de ambientes hospitalares e da comunidade. Essa resistência tem sido relacionada frequentemente à presença dos genes qnrA, qnrB, qnrS (FERRARI et al, 2011; VASCONCELOS et al., 2010), sendo os mais prevalentes qnrB e qnrS.

A resistência para aminoglicosídeos em $E$. coli é principalmente devido à expressão de enzimas de modificação e diferentes determinantes genéticos foram identificados, tais como: aac (6') -I, aph (3') -I, aac (3) - I, aac (3) -II, aac (3) -III, aac (3) -IV, e ant (2"). Os genes aac e ant são os mais detectados em isolados de $E$. coli tanto da comunidade como de ambientes hospitalares (DOMINGUEZ et al., 2002; SHAW et al, 1993).

Diferentes genes de tet têm sido identificados em isolados de $E$. coli resistente à tetraciclina como: $\operatorname{tet} A$, tetB, tetC, tetD, tetE e tetl. Embora essa classe de antimicrobianos não seja comumente utilizada para tratamento de infecções causadas por $E$. coli, os genes tetA, tetB e tetD são os mais detectados e estão associados ao mecanismo de bombas de efluxo (DOMINGUEZ et al., 2002; ROBERTS, 1996).

A nitrofurantoina age por sofrer redução de nitrorredutases bacterianas para gerar derivados tóxicos que ligam aos ribossomos, fazendo com que a transcrição e tradução sejam prejudicadas. A resistência em E. coli envolve mutações de perda de função em dois genes que codificam nitrorredutases $n f s A$ e nfsB (XAVIER et al., 2014) e os dados sobre sua prevalência são escassos.

Em E. coli já foram descritas vários sistemas de bombas de efluxo, entretanto as bombas da família RND são as mais caracterizadas. São compostas de três partes: uma proteína transportadora ancorada na membrana interna responsável pelo efluxo, uma proteína acessória localizada no espaço periplasmático conhecida também como proteína de fusão e uma proteína localizada na membrana externa (NIKAIDO; TAKATSUKA, 2009; PIDDOCK, 2006b). 
As bombas AcrAB-TolC, em E. coli, é uma das mais estudadas e é homóloga ao sistema MexAB-OprM em Pseudomonas aeruginosa. O perfil de substrato da bomba AcrAB-TolC inclui: corantes catiônicos, como acriflavina, cristal violeta, brometo de etídeo e rodamina; antimicrobianos como as penicilinas, cefalosporinas, fluoroquinolonas, macrolídeos, cloranfenicol, tetraciclinas, novobiocina, rifampicina, ácido fusídico, ácido nalidíxico; detergentes como Triton, SDS e sais biliares, por isso esse sistema está envolvido com a multirresistência (NIKAIDO; TAKATSUKA, 2009).

A tigeciclina, apesar de ser uma droga não prescrita com frequência para infecções acometidas por E. coli, foi desenvolvida para superar os principais mecanismos de resistência a tetraciclina: presença dos genes tet $\mathrm{e}$ as bombas de efluxo. Embora a tigeciclina possa induzir a expressão das bombas, a evasão do efluxo é provavelmente conferida pelo grupo 9-tbutilglicilamido, que impede a tigeciclina de ser reconhecido como um substrato de bomba de efluxo, isto é, a bomba não reconhece mais o substrato pela modificação da estrutura molecular da droga (Bypassing) (LINKEVICIUS et al., 2013; PAGES et al., 2005).

Até o momento, poucos estudos epidemiológicos têm avaliado a prevalência da resistência de $E$. coli em pacientes assintomáticos (AMAYA et al., 2011; BAILEY et al., 2010, MOSQUITO et al., 2012). A maioria dos estudos que avaliam a prevalência foram realizadas em populações sintomáticas, em isolados obtidos a partir de pacientes com infecções do trato urinário infecção ou bacteremias (ERB et al., 2007).

Os dados epidemiológicos brasileiros mostram que a frequência de isolados resistentes podem variar significativamente de região para região ou mesmo de hospital para hospital dentro de uma mesma região geográfica, sendo que o Brasil vem apresentando altos índices de resistência em relação aos países da América do Norte, Europa e Ásia (GALES et al., 2003; LINCOPAN et al., 2006; SADER et al., 2005).

Assim, este estudo ressalta a magnitude do problema da resistência aos antimicrobianos e da urgente necessidade de vigilância e controle desse fenômeno. A utilização de métodos baratos e sensíveis para monitorar a resistência aos antimicrobianos em bactérias comensais podem tornar ferramentas valiosas. 
O uso indevido e indiscriminado de antimicrobianos altera a microbiota intestinal residente levando à diminuição da diversidade e a supressão de microrganismos, tornando um reservatório de resistência, albergando genes silenciosos, desencadeando mutações e a super expressão de bombas de efluxo, além da transferência horizontal de elementos genéticos intra e inter espécies. 


\section{CONCLUSÃO}

Com os dados obtidos neste estudo pode-se concluir que:

1. Através do qPCR foi observada a redução no número de cópias por gramas/fezes de: Bifidobacterium spp., Bacteroides fragilis, Clostridium perfringens, Escherichia coli, Methanobrevibacter smithii e Firmicutes nas amostras das crianças que utilizaram antibióticos em relação ao grupo controle, exceto para Lactobacillus spp. e Parabacteroides distasonis que apresentaram uma quantificação maior no grupo antibiótico.

2. Das amostras avaliadas tanto no grupo controle como no com antibióticos apresentaram alta taxa de isolamento de E. coli.

3. Em relação à presença de $D E C$ foram identificadas no grupo controle: EAEC atípica, EAEC típica, EPEC atípica, ETEC-LT, STEC stx1 e STEC stx2; e no grupo com antibióticos detectou-se EPEC e EAEC atípica.

4. Foi observada resistência para diversas drogas no grupo controle exceto para ciprofloxacina, meropenem e tigeciclina. Em contrapartida, o grupo tratado com antibióticos apresentou alta resistência para todas as drogas avaliadas; caracterizando as cepas desse estudo como MDR.

5. Todos os isolados do grupo controle e antibióticos possuiram diversos genes de resistência, entretanto o gene blakPC foi o único não detectado em isolados do grupo controle.

6. A análise da diversidade genética por AP-PCR mostrou boa discriminação entre os isolados No grupo controle foram verificados grupos genéticos com $85 \%$ de similaridade e no grupo com antibióticos com $86 \%$ de similaridade. Entretanto ambos os grupos demonstram elevada diversidade genética. 


\section{REFERÊNCIAS*}

ABILDGAARD, L. In vitro production of necrotic enteritis toxin $B$, NetB,by netB positive and netB negative Clostridium perfringens originatinf from healthy and diseased broiler chickens. Vet. Microbiol., v. 144, p. 231-235, 2009.

ADLERBERTH, I; WOLD, A. E. Establishiment of the gut microbiota in Western infants. Acta.Pediatr., v.98, p.229-238, 2009.

Agência Nacional de Vigilância Sanitária (ANVISA). Antimicrobianos:bases

teóricas e uso clínico. Brasilia, 2007. Disponivel em:<http//:www.anvisa.gov.br/servicosaude/controle/rede_rm/cursos/rm_control e/opas_web/modulo1/pop.mecanismo.htm >. Acesso em :24 fev.2015.

ALANIS, A. J. Resistance to antibiotics: are we in the post antibiotic era? Arch. Med. Res., v. 6, p. 697-705, 2005.

ALDRED, K. J. et al. Mechanism of quinolone action and resistance. Biochemistry, v.53, p.1565-1574, 2014.

ÁLVAREZ, V. R. et al. Intestinal microbiota, immune system and obesity. Rev.Cub. Invest. Biom., v.29, p.364-397, 2010.

AMAYA, E. et al. Antibiotic resistance patterns of intestinal Escherichia coli isolates from Nicaraguan children. J. Med. Microbiol., v. 60, p. 216-222, 2011.

ANTONOPOULOS, D.A. et al. Repoducible community dynamics of the gastrointestinal microbiota following antibiotic perturbation. Infect. Immun.,v. 77 , p. 2367-2375, 2009.

ARANDA, K.R.S.et al. Evaluation of Multiplex PCRs for Diagnosis of Infection with Diarrheagenic Escherichia coli and Shigella spp. J. Clin. Microbiol., v. 42, n.12, p. 5849-5853, 2004.

ARANDA, K.R.S. et al. Single multiplex assay to identify simultaneously enteropathogenic enteroaggregative, enterotoxigenic, enteroinvasive and Shiga toxin producing Escherichia coli strains in Brazilian children. FEMS Microbiol. Lett., v. 267, p.145-150, 2007.

ARENAS-HERNÁNDEZ, M.M. et al. Clinical implications of enteroadherent Escherichia coli. Curr. Gastroenterol. Rep., v. 14, p. 386-394, 2012.

ARRIETA, M.C. et al. The intestinal microbiome in early life: health and disease. Front. Immunol., v. 5, p.427, 2014.

ASHRAF, R; SHAH, N. P. Review Article Antibiotic resistance of probiotic organisms and safety of probiotic dairy products. Int. Food Res. J., v.18, p. 837-853, 2011.

\footnotetext{
* De acordo com: ASSOCIAÇÃO BRASILEIRA DE NORMAS TÉCNICAS. NBR 6023: Informação e documentação: referências: elaboração. Rio de Janeiro, 2002.
} 
AVILA-CAMPOS, M.J. et al. Genetic diversity of oral Fusobacterium nucleatum isolated from patients with diferente clinical conditions. Rev. Inst. Med. Trop. São Paulo., v. 48, p. 59-63, 2006.

BACKHED, F. et al. Host-bacterial mutualismin the human intestine. Science, v. 307, p.1915-1920, 2005.

BARBOSA, F.H.F. et al. Microbiota indígena do trato gastintestinal. Rev. Biol. Ciên. da Terra., v.10, p.78-93, 2010.

BARTOLONI, A. et al., Multidrug-resistant Commensal Escherichia coli in children, Peru and Bolivia. Emerg. Infec. Dis., v. 12, p. 906-913, 2006.

BASSETTI, M. et al. New antibiotics for bad bugs: where are we? Ann. Clin. Microbiol. Antimicrob., v.28, p. 12:22, 2013.

BAILEY, J.K, et al. Commensal Escherichia coli of healthy humans: a reservoir for antibiotic-resistance determinants. J. Med. Microbiol., v. 59, p.1331-1339, 2010.

BENGMARK, S. Ecological control of the gastrointestinal tract: the role of probiotic flora. Gut, v.42, p. 2-7, 1998.

BERGAN, J. et al. Shiga Toxin. Toxicon, v. 60, p.1085-1087, 2012.

BERTIN, J. et al. Stx2 subtyping of Shiga toxin-producing Escherichia coli isolated from cattle in France: detection of a new Stx2 subtype and correlation with additional virulence factors. J. Clin. Microbiol., v. 39, p. 3060-3065, 2001.

BERVOETS, L. et al. Differences in gut microbiota compositiom between obese and lean children: a cross-sectional study. Gut Pathog., v.5, p. 10, 2013.

BEZIRTZOGLOU, E. The intestinal microflora during the first weeks of life. Anaerobe, v.3, p. 173-177, 1997.

BLAIR, J. M. A. et al. Molecular mechanisms of antibiotic resistance. Nature Rev. Microbiol., v. 13, p. 42-51, 2014.

BOENTE, R.F. et al. Detection of resistance genes and susceptibility patterns in Bacteroides and Parabacteroides strains. Anaerobe, v. 16, p. 190-194, 2010.

BONACORSI, S; BINGEN, E. Molecular epidemiology of Escherichia coli causing neonatal meningitis. Int. J. Med. Microbiol., v. 295, p. 373-381, 2005.

BONKOUNGOU, I.J.O. et al. Diarrhoeagenic Escherichia coli detected by 16plex PCR in children with and without diarrhoea in Burkina Faso. Clin. Microbiol. Infec., v. 18, p. 901-906, 2012.

BRUMBAUGH AR, MOBLEY HL. Preventing urinary tract infection: progress toward an effective Escherichia coli vaccine. Expert. Rev. Vaccines, v. 11, p. 663-676, 2012. 
BUERIS, V. et al. Detection of diarrheagenic Escherichia coli from children with and without diarrhea in Salvador, Bahia, Brazil. Mem. Inst. Oswaldo Cruz, v. 102, p. 839-844, 2007.

$\mathrm{BUSH}, \mathrm{K}$. et al. A functional classification scheme for beta-lactamases and its correlation with molecular structure. Antimicrob. Agents Chemother., v.6, p.1211-1233, 1995.

BUFFIE, C. G; PAMER. E. G. Microbiota-mediated colonization resistance against intestinal pathogens. Nat. Rev. Immunol., v. 13, p. 790-801, 2013.

BUSH, K; JACOBY, G. A. Updated functional classification of beta-lactamases. Antimicrob. Agents Chemother.,v. 54, p. 969-976, 2010.

BUSH, K.; FISHER, J. F. Epidemiological expansion, structural studies and clinical challenges of new $\beta$-lactamases from gram-negative bactéria. Annu. Rev. Microbiol., v. 65, p. 455-478, 2011.

CETINKAYA, Y. et al. Vancomicin-resistant enterococci. Clin. Microbiol.Rev., 13, p. 686-707, 2000.

CIVARDI, E. et al. Enteral nutrition and infections: the role of human milk. Early Hum. Dev., v. 90S1, p. S57-S59, 2014.

CLEMENTS, A. et al. Infection strategies of enteric pathogenic Escherichia coli. Gut Microbes., v. 3, p. 71-87, 2012.

CLERMONT O. et al. The Clermont Escherichia coli phylo-typing method revisited: improvement of specificity and detection of new phylo-groups. Env. Microbiol. Rep., v.5, p. 58-65, 2013.

CLINICAL AND LABORATORY STANDARDS INSTITUTE. Performace standards for antimicrobial susceptibility testing, twenty-third information supplement. CLSI document M100-S23, USA, 2013.

COLLINS, M. D. et al. The phylogeny genus Clostridium: proposal of five new genera and eleven new species combinations. Int. J. Syst. Bacteriol., v. 44, p. 812-826, 1994.

COX, L.M.; BLASER, M.J. Pathways in Microbe-Induced Obesity. Cell Metab., v. 17, p.883-894, 2013.

CROSWELL, A. et al. Prolonged Impact of Antibiotics on Intestinal Microbial Ecology and Susceptibility to Enteric Salmonella Infection. Infect. Immun., v. 77, p. 2741-2753, 2009.

CROXEN, M.A; FINLAY, B.B. Molecular mechanisms of Escherichia coli pathogenicity. Nat. Rev., v.8, p. 26-38, 2010. 
DAVIES, J; DAVIES, D. Origins and evolution of antibiotic resistance. Microbiol. Mol. Biol. Rev., v. 74, p. 417-433, 2010.

DE GREGORIS, T. B.et al. Improvement of phylum- and class-specific primers for real-time PCR quantification of bacterial taxa. J. Microbiol. Methods, v. 86, p. 351-356, 2011.

DE La COCHETIERE, M.F. et al. Resilience of the Dominant Human Fecal Microbiota upon Short-Course Antibiotic Challenge. J. Clin. Microbiol., v.43, p. 5588-5592, 2005.

DERMOUMI H. L; ANSORG, R. A. Isolation and antimicrobial susceptibility testing of fecal strains of the archae on Methanobrevibacter smithii. Chemotherapy, v.47, p. 177-183, 2001.

DiGIULIO, D.B. et al. Microbial prevalence, diversity and abundance in amniotic fluid during preterm labor: a molecular and culture-based investigation. PLoS one., v. 3, p. e3056, 2005.

DRIDI, B. et al. The antimicrobial resistance pattern of cultured human methanogens reflects the unique phylogenetic position of Archaea. J. Antimicrob. Chemother. v.66, p.1-7, 2011.

DOMÍNGUEZ, E. et al. Mechanisms of antibiotic resistance in Escherichia coli isolates obtained from healthy children in Spain. Microb. Drug Resist., v. 8, p. 321-327, 2002.

ERB, A. et al. Prevalence of antibiotic resistance in Escherichia coli: overview of geographical, temporal, and methodological variations. Eur. J. Clin. Microbiol. Infect. Dis., v. 26, p. 83-90, 2007.

FANARO, S. et al. Intestinal microflora in early infancy: composition and development.Acta Paediatr. Suppl., v.91, p.48-55,2003.

FERNANDES, M. R. et al. Presence of Shiga toxin 2e-producing Escherichia coli and atypical enteropathogenic E. coli in an asymptomatic child. J. Med. Microbiol. Case Reports., v. 1, p. e000001-e 000003, 2014.

FERRARI, R. et al., Plasmid-mediated quinolone resistance by genes qnrA1 and qnrB19 in Salmonella strains isolated in Brazil. J. Infect. Dev. Ctries., v. 5, p. 496-498, 2011.

FLECKENSTEIN, J. M. et al. Molecular mechanisms of enterotoxigenic Escherichia coli infection. Microbes Infect., v. 12, p 89-98, 2010.

FOUHY, F. et al. A degenerate PCR-based strategy as a means of identifying homologues of aminoglycoside and $\beta$-lactamresistance genes in the gut microbiota. BMC Microbiol., v. 5, p. 14:25, 2014. 
FUNKHOUSER, L.J., BORDENSTEIN, R.S. Mom knows best: the universality of maternal microbial transmission. PLoS Biol., v.11, p.e1001631, 2013.

GALES, A. C et al. Antimicrobial Susceptibility of Klebsiella pneumoniae Producing Extended-Spectrum beta-lactamase (ESBL) Isolated in Hospitals in Brazil. Braz . J. Infect. Dis., v. 1, p. 196-203, 1997.

GALES, A. C. et al. Dissemination in distinct Brazilian regions of na epidemic carbapenem-resistant Pseudomonas aeuruginosa producing SPM metallo- $\beta$ lactamses. J. Antimicrob. Chemeoth., v. 52, p. 699-702, 2003.

GARCIA, P. G. et al. Occurrence and antimicrobial drug susceptibility patterns of commensal and diarrheagenic $E$. coli in fecal microbiota from children with and without acute diarrhea. J. Microbiol., v. 49, p. 46-52, 2011.

GUARDABBASI, L.C. Modes of antimicrobial action and mechanisms of bacterial resistance. 2006.In: AARESTRUP, F.M (ed.) Antimicrobial resistance in bacteria of animal origin. Washigton, D.C.: American Society for Microbiology, p. 326-333, 2006.

GOMES, T.A.et al. Adhesin-encoding genes from shigatoxin-producing Escherichia coli are more prevalente in atypical than in typical enteropathogenic E. coli. J. Clin. Microbiol., v. 49, p. 3334-3337, 2011.

GONSALBES, M.J. et al. Meconium microbiota types dominated by lactic acid or enteric bactéria are differentially associated with maternal eczema and respiratory problems in infants. Clin. Exp. Allergy, v. 43, p. 198-211, 2013.

HASCOET, J. M. et al. Effect of formula composition on the development of infant gut microbiota.J. Pediatr. Gastroenterol.Nutr., v.52, p.756-762, 2011.

HILL, M.J; Drasar, B.S. The normal colonic bacterial flora. Gut, v.16, p.318-323, 1975.

HUANG, D.B. et al. A review of an emerging enteric pathogen: enteroaggregative Escherichia coli. J. Med. Microbiol., v. 55, p. 1303-1311, 2006.

HUOVINEN, P. Resistance to trimethoprim-sulfamethoxazole. Clin. Infec. Dis., v. 32, p. 1608-1614, 2001.

HUYS, G, et al., Escherichia albertii sp. nov., a diarrhoeagenic species isolated from stool specimens Bangladeshi children. Int. J.Syst. Evol. Microbiol., v.53, p. 807-810, 2003.

IDSA, Infectious Diseases Society of America. et al. Combating Antimicrobial Resistance: Policy Recommendations to Save Lives. Clin. Infect. Dis., v.5, p.S397-428, 2011. 
ISERI, L. et al. The prevalence of Enterotoxigenic E. coli from the stools of children aged 0-10 years with diarrhea in Mid -Anatolia region, Turkey. Braz. J. Microbiol., v.42, p. 243-247, 2011.

HOLZAPFEL, W.H. et al. Overview a gut flora and probiotics. Int. J. Food Microbial., v.41, p.85-101, 1998.

JACOBY, G.A. AmpC beta-lactamases. Clin. Microbiol. Rev., v. 22, p. 161182, 2009.

JAKOBSSON, H.E. et al. Short-term antibiotic treatment has differing long-term impacts on the human throat and gut microbiome. PLoS One, v. 5, p. e9836, 2010.

JERNBERG, C. et al. Long-term impacts of antibiotic exposure on the human intestinal microbiota. Microbiology, v. 156, p. 3216-3223, 2010.

JIMENÉZ, E. et al. Isolation of commensal bacteria from umbilical cord blood of healthy neonates born by cesarean section. Curr. Microbiol., v. 51, p. 270-274, 2005.

JOHNSON JR, RUSSO TA. Molecular epidemiology of extraintestinal pathogenic (uropathogenic) Escherichia coli. Int. J. Med. Microbiol., v. 295, p. 383-404, 2005.

KANG, S. et al. Dysbiosis of fecal microbiota in Crohn's diseases patients as revealed by a custom phylogenetic microarray. Inflamm. Bowel.Dis., v.16, p. 2034-2042, 2010.

KAPER, J.B. et al. Pathogenic Escherichia coli. Nature, vol.2, p. 123-140, 2004.

KAPLAN, J. B. et al. Population Structure and Genetic Diversity of Actinobacillus actinomycetemcomitans Strains Isolated from localized Juvenile Periodontitis Patients. J. Clin. Microbiol., v. 40, p. 1181-1187, 2002.

KLEESSEN, B. et al. Culture based knowledge on biodiversity development and stability of human gastrointestinal microflora. Microbiol. Ecol. Health Dis., v. 2, p. $53-63,2000$.

KOVATCHEVA-DATCHARY, $P$ et al. Tools for the tract: understanding the functionality of the gastrointestinal tract. Therap. Adv. Gastroenterol., v. 2, p. 9-22, 2009.

LEE, D.H. et al. Quantitative Detection of Residual E. coli Host Cell DNA by Real-Time PCR. J. Microbiol. Biotechnol., v.20, n.10, 1463-1470, 2010.

LIN, H. C. et al. Oral probiotics reduce the incidence and severity of necrotizing enterocolitis in very low birth infants. Pediatrics, v.3, p. 1-4, 2005. 
LINCOPAN, N. et al. Enterobacteria producing extend-spectrum betalactamases and IMP-1 metallo-beta-lactamases isolated from Braziliand hospitals. J. Med. Microbiol., v. 55, p. 1611-1613, 2006.

LINKEVICIUS, M. et al. Mechanisms and fitness costs of tigecycline resistance in Escherichia coli. J. Antimicrob. Chemother., v; 68, p. 2809-2819, 2013.

LIVERMORE, D.M. beta-Lactamases in laboratory and clinical resistance. Clin. Microbiol. Rev., v. 8, p. 557-584, 1995.

LLANCO, L. A. et al. Sialidase Production and Genetic Diversity in Clostridium perfringens Type A Isolated from Chicken with Necrotic Enteritis in Brazil. Curr. Microbiol., v. 70, p. 330-337, 2015.

LOZER, D. M. et al. Genotypic and phenotypic analysis of diarrheagenic Escherichia coli strains isolated from Brazilian children living in low socioeconomic level communities. BMC Infect. Dis., v. 13, p. 418-423, 2013.

MAGALHÃES, J. G. et al. The intestinal ephitelial barrier: how to distinguish between the microbial flora and pathogens. Semin. Immunol., v. 19, p. 106115, 2007.

MAGIORAKOS, A. P. et al. Multidrug-resistant, extensively drug-resistant and pandrug-resistant bacteria: an international expert proposal for interim standard definitions for acquired resistance. Clin. Microbiol. Infect., v. 18, p. 268-281, 2012.

MALINEN, E. et al. Comparison of real-time PCR with SYBR Green I or 5'nuclease assays and dot-blot hybridization with rDNA-targeted oligonucleotide probes in quantification of selected faecal bacteria. Microbiology, v.149, p. 269-277,2003.

MENG, H. Body Weight Selection Affects Quantitative Genetic Correlated Responses in Gut Microbiota. PLoS One, v.9, p. e89862, 2014.

MOLES, L. et al. Bacterial diversity in meconium of preterm neonates and evolution of their fecal microbiota during the firstmonth of life. PLoS one, v.8, p. e66986, 2013.

MONIRA, S. et al. Gut microbiota of healthy and malnourished children in Bangladesh. Front. Microbiol., vol.2, p. 228-232, 2011.

MOREDO, F.A; VIGO, G.B; CAPPUCCIO, J.A; PINEYRO, P; PERFUMO, C.J; GIACOBONI,G.I. Resistencia a lós antimicrobianos de aislamientos de $E$. coli obtenidos de credos de La Republica Argentina. Rev. Arg. Microbiol.,v.39, p. 227- 229, 2007. 
MOREIRA, M.A.S. et al. Multidrug efflux system in gram-negative bacteria. Brazilian J.Microbiol., v.35, p. 19-28, 2004.

MORIN, N. et al. Characterization of the AggR Regulon in Enteroaggregative Escherichia coli. Infect. Immun., v.81, p. 122-132, 2013.

MOSQUITO, S. et al. Molecular mechanisms of antibiotic resistance in diarrhoeagenic Escherichia coli isolated from children. Int. J. Antimicrob. Agents., v.40, p. 544-548, 2012.

MULVEY, M. R. Antimicrobial resistance in hospitals: how concerned should we be? CMAJ., v. 180, p. 408-415, 2009.

NAKANO, V. et al. bft gene subtyping in enterotoxigenic Bacteroides fragilis isolated from children with acute diarrhea. Anaerobe, v.13, p. 1-5, 2007.

NATARO, J.P; KAPER, J.B. Diarrheagenic Escherichia coli. Clin. Microbiol. Rev., v.11, p. 142-201, 1998.

NAVANEETHAN, U.; GIANNELLA, R.A. Mechanisms of infectious diarrhea. Nat. Clin. Pract. Gastroenterol. Hepatol., v. 11, p. 637-647, 2008.

NUNES, M. R. et al Attaching and effacing Escherichia coli and Shiga toxin producing $E$. coli in children with acute diarrhoea and controls in Teresina/PI, Brazil. Trans. R. Soc. Trop. Med. Hyg., v. 106, p. 43-47, 2012.

NICOLI, J.R. Normal gastrointestinal microbiota in domestic animals and human beings. Enferm. Infec. Microbiol., v. 15, p. 183-190, 1995.

NICOLI, J.R.; VIEIRA, L.Q. Microbiota gastrointestinal normal na doença e na saúde. Gastroenterology, v. 1, p. 1037-1047, 2004.

NIKAIDO, H; TAKATSUKA, Y. Mechanisms of RND multidrug efflux pumps. Biochim. Bioph. Acta., v. 1794, p. 769-781, 2009.

NORD, C.E; EDLUND, C. Ecological effect of antimicrobial agents on the human intestinal microflora. Microbiol. Ecol. Health Dis., v. 4, p.193-207, 1991.

OHARA, J. A. et al. Molecular epidemiology of KPC-producing Escherichia coli: occurrence of ST131-fimH30 subclone harboring pKpQIL-like IncFIlk plasmid. Antimicrob. Agents Chemother., v. 58, p. 4234-4237, 2014.

PAGÈS, J.M. et al. Inhibitors of efflux pumps in gram-negative bactéria. TRENDS Molec. Med., v.11, p. 382-389, 2005

PALMER, C. et al. Development of the human infant intestinal microbiota. PloS Biol., v. 5, p. 1556-1573, 2007. 
PANDA, S. et al. Short-Term Effect of Antibiotics on Human Gut Microbiota. PLoS One, v.9, p. e95476, 2014.

PAVEZ, M. et al. Emergence of carbapenem-resistant Escherichia coli producing CMY-2-type AmpC $\beta$-lactamase in Brazil. J. Medical Microbiol., v.57, p. 1590-1592, 2008.

PEIRANO, G. et al. Occurrence of integrons and antimicrobial resistance genes among Salmonella enterica from Brazil. J. Antimicrob. Chemother., v. 58, p. 305-309, 2006.

PEIRANO, G. et al. Global incidence of carbapenemase-producing Escherichia coli ST131. Emerg. Infect. Dis., v. 20, p. 1928-1931, 2014.

PEIRANO, G; PITOUT, J. D. Molecular epidemiology of Escherichia coli producing CTX-M beta-lactamases: the worldwide emergence of clone ST131 O25:H4. Int. J. Antimicrob. Agents., v. 35, p. 316-321, 2010.

PENDERS, J. Factors influencing the composition of the intestinal microbiota in early

Pediatrics, v.118, p. 511-521, 2006.

PÉREZ-COBAS, A. E. et al. Gut microbiota disturbance during antibiotic therapy: a multi-omic approach. Gut, v. 62, p. 1591-1601, 2013.

PIDDOCK, L.J.V. Clinically relevant chromosomally encoded multidrug resistance efflux pumps in bacteria. Clin. Microbiol. Rev., v. 19, p. 382-402, 2006a.

PIDDOCK, L.J.V. Multidrug-resistance efflux pumps? Not just for resistance. Nat. Rev. Microbiol., v.4, p. 629-636, 2006 b.

POETA, P. et al. Antimicrobial resistance and the mechanisms implicated in faecal enterococci from healthy humans, poultry and pets in Portugal. Inter. J. Antimicrobial. Agents., v. 27, p. 131-137, 2006.

PONNUSAMY, K. et al. Microbial community and metabolomic comparison of irritable bowel syndrome faeces. J. Med. Microbiol., v. 60, p. 817-827, 2010.

PORRES-OSANTE, N. et al. Emergence of a multiresistant KPC-3 and VIM1 carbapenemase-producing Escherichia coli strain in Spain. J. Antimicrob. Chemother., v. 69, p. 1792-1795, 2014.

POWERS, J.H. Antimicrobial drug development- the past, the present and the future.Clin. Microbiol. Infec., v.62, n.4,p. 23-31, 2004.

PHILLIPS, I. et al. Does the use of antibiotics in food animals pose a risk to human health? A critical review of published data. J. Amicrob. Chemother., v.53, n.1, p.28-52. 
QUEIROZ, M. L. et al. Characterization of extended-spectrum beta-lactamases, antimicrobial resistance genes, and plasmid contente in Escherichia coli isolates from diferente sources in Rio de Janeiro, Brazil. Diagn. Microbiol. Infect. Dis., v. 74, p. 91-94, 2012.

RAFII, F. et al. Effect of treatment with antimicrobial agents on the human colonic microflora. Therap. Clin. Risk Manag., v. 4, p. 1343-1347, 2008.

RAMAZANZADEH, R. et al. Genetic diversity in clinical isolates of Escherichia coli by enterobacterial repetitive intergenic consensus (ERIC)-PCR technique in Sanandaj hospitals. Iranian J. Microbiol., v.5, p. 126-133, 2013.

RILEY, T.V. From obscurity to 'superbug': the rise of $C$. difficile. Heath Infect., v.15, p. 59-61, 2010.

ROBERTS M. C.Tetracycline resistance determinants: mechanisms of action, regulation of expression, genetic mobility, and distribution. FEMS Microbiol. Rev., v.19, p. 1-24, 1996.

ROCHA, D. P. et al. Coordenação de metais a antibióticos como uma estratégia de combate à resistência bacteriana. Quim. Nova., v. 34., p. 111118, 2011.

RUSSELL, D.A. et al. Metabolic activies and probiotic potential of bifidobacteria. Inter.J. Food Microbiol.,v. 149, p. 88-105, 2011.

SAAVEDRA, M; B; DATILLO, A. M. Early development of intestinal microbiota: implications for future health. Gastroenterol. Clin. North. Am., v.41, p. 717731, 2012.

SADER, H.S. et al. Cefdinir activity against contemporary North American isolates from community- acquired urinary tract infections. Int. J. Antimicrob. Agents., v. 25., p. 89-92, 2005.

SÁENZ, Y. Caracterizacion fenotipica y genotipica de la resistencia a antibioticos en cepas de Escherichia coli no patogenas de alimentos y de la microflora intestinal de humanos y animales. 2004. 89 p. Dissertacion de Doutoramento na area de Bioquimica e Biologia Molecular. Universidade de La Rioja, 2004.

SÁEZ-LLORENS, X. et al. Impact of an antibiotic restriction policy on hospital expenditures and bacterial susceptibilities: a lesson from a pediatric institution in a developing country. Pediatr Infect Dis J., v. 19, p. 200-206, 2000.

SAMB-BA, B. et al. MALDI-TOF Identification of the Human Gut Microbiome in People with and without Diarrhea in Senegal. PLoS One, v.9, p. e87419,2014.

SANDEGREN, L. et al. Nitrofurantoin resistance mechanism and fitness cost in Escherichia coli. J. Antimicrobial Chemoth., v. 62, p. 495-503, 2008. 
SARANTUYA, J. et al. Typical enteroaggregative Escherichia coli is the most prevalent pathotype among E. coli strains causing diarrhea in Mongolian children. J Clin. Microbiol., v.42, p.133-139, 2004.

SATAKORI, S. et al., Bifidobacterium and Lactobacillus DNA in the human placenta. Lett. Appl.Microbiol., v. 48, p. 8-12, 2009.

SCALETSKY, I. C. et al. Diffusely adherent Escherichia coli as a cause of acute diarrhea in Young children in Northeast Brazil: a case-control study. J. Clin. Microbiol., v. 40, p. 645-648, 2002.

SEFTON, A. M. Mechanisms of antimicrobial resistance: their clinical relevance in the new millenium. Drugs, v. 62, p. 557-566, 2002.

SEPP, E. et al. The occurrence of antimicrobial resistance and class 1 integrons among comensal Escherichia coli isolates from infants and elderly persons. Ann. Clin. Microbiol. Antimicrob., v.8, p. 34, 2009.

SETHABUTR, O. et al. Detection of Shigellae and enteroinvasive Escherichia coli by amplification of the invasion plasmid antigen HDNA sequence in patients with dysentery. J. Infect. Dis.,v.167, p.458-61,1993.

SILVA, K; LINCOPAN, N. Epidemiology of extended-spectrum beta-lactamases in Brazil: clinical impact and implications for agribusiness. Bras. Patol. Med. Lab., v. 48, p. 91-99, 2012

SIRAGUSA, G.R. et al. Quantitative analysis of the intestinal bacterial community in one-to three week old commercially reared broiler chickens fed conventional or antibiotic free vegetables based diets. J. App. Microbiol., v. 102, p.1138-1149, 2007.

SHAW, K.J. ET AL. Molecular genetics of aminoglycoside resistance genes and familial relationships of the aminoglycoside-modifying enzymes. Microbiol. Rev., v. 57, p. 138-163, 1993.

SHEN, J. et al. The gut microbiota,obesity and insulin resistance. Mol. Aspects. Med. v.34, p. 39-58, 2013.

STEWART, J.A. et al. Investigations into the influence of host genetics on the predominant eubacteria in the faecal microbiota of children. J. Med. Microbiol., v.54, p. 1239-1242, 2005.

SOLEIMANI, N. et al. Frequency distribution of genes encoding aminoglycoside modifying enzymes in uropathogenic $E$. coli isolated from Iranian hospital. BMC Res. Notes, v. 7, p. 842-847, 2014. 
SPELLBERG, B. et al. The epidemic of antibiotic-resistant infections: a call to action for the medical community from the Infectious Diseases Society of America. Clin. Infect. Dis., v. 46, p.155-164, 2008.

TANNOCK, G.W. Molecular assessment of intestinal microflora. Am. J. Clin. Nutr., v. 73, p. 410S-414S, 2001.

TOIVANEN, P. et al. Influence of major histocompatibility complex on bacterial composition of fecal flora. Infect. Immun., v.69, p. 2372-2377, 2001.

TONG, J.et al. Application of quantitative real-time PCR for rapid identification of Bacteroides fragilis group and related organisms in human wound samples. Anaerobe, v.17, p. 54-68, 2011,

VAN DER WAAIJ, L.A et al. Bacterial populations analysis of human colon and terminal ileum biopsies with 16S rRNA based fluorescent probes: commensal bacteria live in suspension and have no direct contact with epithelial cells. Inflamm. Bowel Dis., v.11, p. 865-871, 2005.

VAN HOEK, A. H. et al. Acquired antibiotic resistance genes: na overview. Front. Microbiol., v.2, p.203, 2011.

VASCONCELOS, F. Perfil de resistência antimicrobiano de E. coli isoladas do açude Santo Anastácio, Ceará, Brasil. Arquivo do Instituto Biológico, São Paulo, v. 77, p. 405-410, 2010.

VIANA, A.L.M. Extended-spectrum b-lactamases in Enterobacteriaceae isolated in Brazil carry distinct types of plasmid-mediated quinolone resistance genes. $\mathbf{J}$. Med. Microbiol., v.62, p. 1326-1331, 2013.

VIDAL, J.E. et al. Patogénesis molecular, epidemiologia y diagnóstico de Escherichia coli enteropatógena. Salud Publica Mex.,v. 49, p.376-386, 2007.

XAVIER, B. B. et al. Complete Genome Sequences of Nitrofurantoin-Sensitive and-Resistant Escherichia coli ST540 and ST2747 Strains. Genome Announc., v. 2, p. e00239-14, 2014.

ZOETENDL, E.G. et al. DNA isolation protocols affect the detection limit of PCR approaches of bacteria in samples from the human gastrointestinal tract. Syst. Appl. Microbiol., v.24, p.405-410,2001.

ZURFLUH, K. et al. Quinolone Resistance Mechanisms among ExtendedSpectrum Beta-Lactamase (ESBL) Producing Escherichia coli Isolated from Rivers and Lakes in Switzerland. PLoS One, v. 9, p. e95864, 2014.

WALSH, C. Antibiotics that block DNA replication and repair: the quinolones. In: (Ed.). Antibiotics: Actions, origins, resistance. Washigton DC:. American Society for Microbiology, 2003. 
WANG, R.F. et al. PCR detection and quantification of predominant anaerobic bacteria in human and animal fecal samples. App. Envir.Microbiol., v.4, p.1242-1247,1996.

WEBBER, M.A; PIDDOCK, L.J.V. The importance of efflux pumps in bacterial antibiotic resistance. J. Antimicrobial Chemother., v.51, p. 9-11, 2003.

WEINTRAUB, A. Enteroaggregative Escherichia coli: epidemiology, virulence and detection. J. Med. Microbiol., v. 56, p. 4-8, 2007.

WEXLER, H.M. Bacteroides: the good, the bad, and the nitty-gritty. Clin. Microbiol. Rev., v.20, p. 593-621, 2007.

WIEDEMANN, B.; HEISIG, P. Mechanisms of quinolone resistance. Infection, v. 22, p. 73-79, 1994.

WILLIAMS, J.G.K. et al. DNA polymorphisms amplified by arbitrary primers are useful as genetic markers. Nucleic Acids Res., vol. 18, p. 6531-6535, 1990

WINKLER, P. et al. Molecular and cellular basis of microflora host interactions. J. Nutr., v.137, p. 756S-772S, 2007.

WOERTHER, P.L. et al. Trends in human fecal carriage of extended- $\beta$ lactamases in the community: toward the globalization of CTX-M. Clin. Microbiol. Rev., v. 26, p. 744-758-,2003.

WRIGHT, G. D. Something old, something new: revisiting natural products in antibiotic drug discovery. Can. J. Microbiol. v. 60, p.147-54, 2014.

WOLOWCZUK, I. et al. Feeding Our Immune System: Impact on Metabolism. Clin. Devol. Immuol., v. 639803, p. 1-19, 2008.

WOO, P.C.Y. et al. Facilitation of horizontal transfer of antimicrobial resistance by transformation of antibiotic-induced cell-wall-deficient bactéria. Med. Hypotheses, v. 61, p. 503-508, 2003.

YANG, T. et al., The association between occurrence of plasmid-mediated quinolone resistance and ciprofloxacin resistance in Escherichia coli isolates of different origins. Vet. Microbiol., v. 170, p. 89-96, 2014.

YOON, S. S. et al. Functional genomic and metagenomic approaches to understanding gut microbiota-animal mutualismo. Curr. Opin. Microbiol., v. 24, p. 38-46, 2015. 